\title{
Revisitando a prática assistencial: a subjetividade como matéria para a reorganização do processo de trabalho na Enfermagem
}

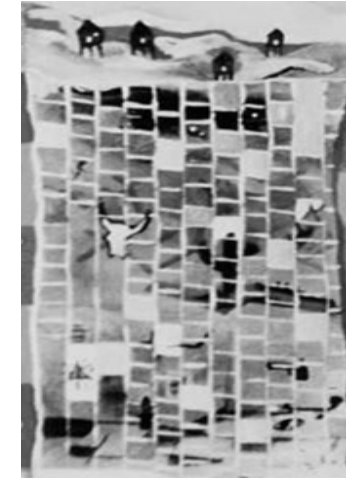

Maria José Bistafa Pereira ${ }^{1}$

Silvana Martins Mishima²

PEREIRA, M.J.B., MISHIMA, S.M. Revisiting health care practice: subjectivity as material for the reorganization of the nursing process, Interface - Comunic, Saúde, Educ, v.7, n.12, p.73-90, 2003.

Nursing practice in the Home Care Service (SAD - Serviço de Assistência Domiciliar) of the Municipal Healthcare Department of the city of Ribeirão Preto in the state of São Paulo, Brazil, is the object of this investigation, whose purpose is to analyze the process of home care, pointing out the production of subjectivities and of possibilities concerning healthcare work. This study was empirical and qualitative, relying on concepts derived from the institutionalist movement. The subjects were nurses working in the SAD (Home Care Service). The technique used to collect empirical data was the focus group. The ordering of data was carried out based on the Discourse of the Collective Subject (DCS) method. Results confirmed SAD (Home Care Service) potential as an agent for the transformation of healthcare/nursing practice and the possibility of its gradual incorporation into the practice of the nurses that do this type of work. SAD (Home Care Service) experience has enabled selfquestioning, reflection and a review of conduct. The authors stress the importance ascribed to light technologies for healthcare work and, primarily, for home care, incorporating the subjective dimension inherent to all production. It was also possible to show that this type of work carries with it limitations and frustrations, but that involvement, creativity, responsibleness and satisfaction are also attached to it. The process of change is recognized as being slow, requiring that the worker be willing to constantly accept being overseen and to review the work process.

KEY WORDS: Home-based healthcare; Nursing; private Nursing practice.

A prática da enfermeira no Serviço de Assistência Domiciliar (SAD) da Secretaria Municipal de Saúde de Ribeirão Preto, São Paulo, constitui o objeto desta investigação, visando analisar o processo de assistência domiciliar, apontando para produção de subjetividades e de possibilidades para o trabalho em saúde. Trata-se de pesquisa empírica, qualitativa, utilizando conceitos relacionados ao movimento institucionalista, sendo os sujeitos enfermeiras que atuam no SAD. Para coleta do material empírico, foi utilizada a técnica do grupo focal. A ordenação dos dados ocorreu pelo método do Discurso do Sujeito Coletivo - DSC. Os resultados confirmam a potencialidade do SAD se configurar como dispositivo para a transformação da prática de saúde/enfermagem e ir processualmente se instalando na prática das enfermeiras que realizam esse trabalho. A vivência no SAD tem oportunizado auto-questionamento, reflexão e revisão de condutas. Destaca-se a importância atribuída às tecnologias leves para o trabalho em saúde e, principalmente, para a assistência domiciliar, incorporando a dimensão subjetiva inerente a toda produção. Foi possível evidenciar que é um trabalho vivenciado com limitações, frustrações, mas também com envolvimento, criatividade, responsabilização e satisfação, reconhecendo o processo de mudança como lento, no qual o trabalhador precisa estar disposto a constantemente aceitar ser revisto e rever o processo de trabalho.

PALAVRAS-CHAVE: Cuidados domiciliares de saúde; Enfermagem; prática privada de Enfermagem.

\footnotetext{
${ }^{1}$ Professora do Departamento de Enfermagem Materno-Infantil e Saúde Pública da Escola de Enfermagem de Ribeirão Preto da Universidade de São Paulo. <zezebis@eerp.usp.br>

2 Professora do Departamento de Enfermagem Materno-Infantil e Saúde Pública da Escola de Enfermagem de Ribeirão Preto da Universidade de São Paulo. < smishima@eerp.usp.br>
} 
Apresentando o objeto, objetivo e suporte teórico A temática deste estudo aborda a prática da Enfermagem em Saúde Coletiva, dentro do processo mais recente de municipalização do setor Saúde, principalmente a partir do início da década de 1990, tendo como foco o trabalho da enfermeira com o olhar voltado ao Serviço de Assistência Domiciliar (SAD) da Secretaria Municipal de Saúde de Ribeirão Preto (SMS/ RP).

O SAD emergiu de um processo de reflexão de um grupo de enfermeiras da SMS-RP e de docentes da Escola de Enfermagem de Ribeirão Preto da Universidade de São Paulo, sobre a prática de Enfermagem e o modelo de atenção à saúde, predominantes nas unidades municipais de saúde de Ribeirão Preto, na primeira metade da década de 1990. Nesse período, as enfermeiras da SMS manifestavam insatisfação com o desenvolvimento das ações de enfermagem, essencialmente voltadas para o controle interno das unidades e à execução de procedimentos de enfermagem auxiliares da consulta médica, articulando suas atividades "ao modelo tecnológico de organização do trabalho nas Unidades Básicas de Saúde, que é o de assistência médica individual” (Almeida, 1991, p.233).

Essa insatisfação tornou-se geradora de energia e fez com que um grupo de enfermeiras repensasse, teorizasse e olhasse para as necessidades dos usuários relacionadas à Saúde, compartilhando experiências e acreditando ser possível reinventar, surgindo, assim, o início da construção do SAD, cujos objetivos iniciais apresentavam caráter assistencial pautado na integralidade das práticas sanitárias, na perspectiva de um modelo de atenção à saúde centrado nos princípios do Sistema único de Saúde (SUS).

É objetivo deste estudo analisar como são tecidas as tecnologias presentes no processo de assistência domiciliar, indicando a produção de subjetividades e as possibilidades de contribuir para a reorientação do trabalho em saúde.

Por tecnologias, estamos tomando as apresentadas por Mehry et al. (1997), que as classificam em duras, leves-duras e leves, considerando tecnologias duras os equipamentos, as máquinas e que encerram trabalho morto, fruto de outros momentos de produção, condensam em si saberes $e$ fazeres bem estruturados, já materializados - acabados, prontos. As tecnologias leve-duras referem-se aos saberes agrupados que direcionam o trabalho, como as normas, os protocolos e o conhecimento produzido em áreas específicas do saber. Caracterizam-se por conter trabalho capturado, com possibilidades de expressar trabalho vivo, encaminhando-se para as relações constituídas e constituintes nos espaços intercessores ${ }^{3}$, e são potência de expressão de trabalho vivo em ato. As tecnologias leves são as tecnologias de relações, quais sejam: a de produção de vínculo, autonomização, acolhimento e gestão como uma forma de governar processos de trabalho.

Nesse sentido, o movimento institucionalista tornou-se um grande aliado na análise do objeto de investigação deste estudo. Em suas características mais gerais, o movimento institucionalista é o conjunto de escolas, comportando diversas tendências, mas independentemente das divergências entre eles, todas se "propõem propiciar, apoiar, deflagrar

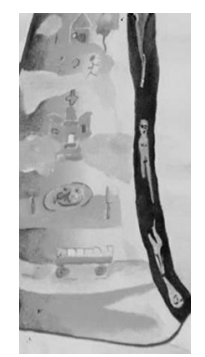

\footnotetext{
${ }^{3}$ Aqui estamos chamando de espaços intercessores os momentos de encontro entre trabalhadorese usuários em que se estabelecem relações únicas e com a perspectiva de integração e intervenção (Merhy, 1994; Merhy et al., 1997).
} 


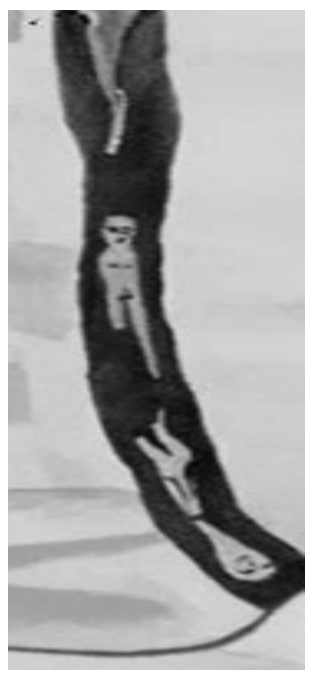

${ }^{4}$ As aspas indicam nossa concordância com Baz e Barriga (1991 p.135), quando alertam que nas pesquisas sociais os dados não são "naturais" e não estão prontos na natureza, são produzidos socialmente, são discursos. com comunidades, nos coletivos, nos conjuntos de pessoas, processos de auto análise e processos de autogestão" (Baremblitt, 1994, p.14). Outro ponto em comum é a concepção da sociedade como uma rede, um tecido de instituições, entendendo aqui por instituições, as composições lógicas que regem as relações e o comportamento humano, as quais podem adquirir a configuração de leis, de normas, porém, mesmo sem esta configuração, regulam as relações e os padrões de comportamento dos homens na sociedade.

Duas vertentes são plasmadas nas instituições, a do instituinte e do instituído, consideradas como forças produtoras e produtos do processo das relações. A instituinte, revestida de um caráter processual, significa "[...] forças que tendem a transformar as instituições ou também a estas forças que tendem a fundá-las [...] são as forças produtivas de códigos institucionais." Por instituído, temos o produto, o resultado das forças de transformação, "é o efeito da atividade instituinte" apresenta uma característica estática, o que não deve ser entendido como uma forma maniqueísta de valores, respectivamente, boa e ruim, pois segundo Baremblitt (1994, p.32-3) "o instituinte careceria completamente de sentido se não se plasmasse, se não se materializasse nos instituídos. Por outro lado, os instituídos não seriam úteis, não seriam funcionais se não estivessem permanentemente abertos à potência instituinte”.

Paralelamente, no nível organizacional estão as atividades "organizantes" e as "organizadas". As primeiras são revestidas de criticidade e transformação, enquanto aquelas que até são necessárias, como os fluxogramas, mas com tendência "natural" a cristalizar-se, são as "organizadas". Estando a vida social em processo constante de transformação na perspectiva de buscar realizações, felicidade, prazer, faz-se necessário entender que esse processo é regulado por vertentes relacionadas dialéticamente, sendo elas: instituído/instituinte; organizado/organizante (Baremblitt, 1994, p.33).

Estamos, assim, ancorando também nossos olhares nessa lógica composta de forças e movimentos dinâmicos/congelados, por reconhecermos na prática de saúde /enfermagem tais características e por acreditarmos que esse movimento nos possibilitará recuperar a dimensão subjetiva inerente ao processo de trabalho em saúde.

\section{O percurso metodológico}

Considerando esses aspectos, elegemos o grupo focal como instrumento para "coleta de dados". Inicialmente, obtivemos o material necessário à análise proposta, captando os aspectos implícitos e explícitos da prática de enfermagem no SAD, sendo as enfermeiras os "principais" sujeitos da investigação.

Morgan (1997) define grupo focal como uma técnica de pesquisa que coleta dados por meio da interação grupal, cujo tópico abordado é determinado pelo pesquisador. Na essência, é o seu interesse que proporciona o foco, contudo os dados são trazidos pela interação grupal.

Os grupos focais proporcionam: o pensar coletivo de uma temática que faz parte da vida das pessoas, conhecer o processo dinâmico de interação 
entre os participantes; observar como as controvérsias se expressam e são resolvidas, além de possibilitar a reprodução de processos de interação que ocorrem fora dos encontros grupais.

Selecionamos para participar da investigação, oito enfermeiras pertencentes ao Distrito de Saúde Castelo Branco (SMS/RP), com atuação no $S A D$, que realizavam assistência domiciliar a usuários que necessitassem seguimento. Realizamos dois encontros com essas enfermeiras para a coleta dos dados, com intervalo de uma semana, no primeiro semestre de 2001.

Gravamos os grupos focais em fitas K-7 as quais transcrevemos literalmente.

Para ordenação e organização do material empírico produzido nos grupos focais apoiamo-nos no processo metodológico do Discurso do Sujeito Coletivo - DSC, proposta recentemente elaborada por Lefévre et al. (2000), que possibilita organizar o conjunto de discursos verbais emitidos por um dado conjunto de sujeitos sobre um dado tema. Para proceder à ordenação prevê-se a utilização de quatro figuras metodológicas: as expressões-chave (ECHs), pedaços contínuos ou descontínuos da fala que revelam a essência do conteúdo de um dado fragmento que compõe o discurso ou a teoria subjacente; as idéias centrais, expressões lingüísticas que revelam ou descrevem de maneira mais sintética e precisa possível o sentido, ou o sentido e o tema de cada conjunto homogêneo de ECHs; a ancoragem, expressão de uma teoria, ideologia ou crença religiosa que o autor do discurso adota e que está embutida no discurso como se fosse uma afirmação qualquer; e o discurso do sujeito coletivo, uma agregação ou soma não matemática de pedaços isolados de depoimentos, de modo a formar um todo discursivo coerente, em que cada uma das partes se reconheça enquanto constituinte deste todo e este como constituído por estas partes, expressando um posicionamento próprio, distinto, original, específico frente ao tema em investigação. Essas figuras devem ser observadas cuidadosamente para se obter um resultado que expresse uma representação fidedigna daquilo que foi pesquisado.

A análise - refletindo sobre as relações produzidas na Assistência Domiciliar O trabalho em saúde se materializa nas relações do homem com outros homens e com a natureza, para o que se fazem necessárias adaptações ativas a transformações ou manutenções; portanto, o homem é produtor e produto dessas relações e, nesta perspectiva, produzir saúde vai além do resgate unicamente do corpo para a produção.

Entendemos que a criatividade, a adaptação crítica à realidade, a alienação $e$ os processos subjetivos estão presentes no emaranhado da produção em saúde. Bleger (1989, p.56) afirma que "entre os instrumentos sociais de alienação estão, em lugar relevante, o ensino e a forma com que - em geral - se realiza: desumanizada e desumanizante". Isto também podemos transportar, sem medo de errar, para a forma com que em geral, se age na produção de saúde.

Para as enfermeiras, a assistência domiciliar proporciona reflexão $e$ revisão na forma como os trabalhadores vêm estabelecendo as relações com os usuários ao adentrarem no domicílio, como podemos observar no fragmento: 


\begin{abstract}
Quando você vai na casa, você percebe que a mãe tem vergonha de falar pra você, lá no hospital, que ela não tinha o que comer, pois não tinha nada. A hora em que você [...] se depara com aquilo, que pára de falar um pouquinho, escuta e vê [...], você vê a diferença que faz algumas coisas, além de você ver e orientar no posto, no hospital e ir lá [...]. Conhecer o lado de lá, porque é uma coisa você falar de branco, lá na sua área, sentar, orientar e outra coisa é você ir lá na casa dela e sentar na cadeira, no chão, no sofá, na cama. Lá você é um estranho [...]. Admito que eu fiz muita visita errada, e como! De você dar a receitinha pronta, de estar curando o umbigo com éter? A mãe respondia: 'Ah, estou pondo isto, ah!' e você afirmava que tinha que colocar o éter, daquela maneira incisiva. E não buscava a cultura porque ela pôs isso ou aquilo. (DSC)
\end{abstract}

Este fragmento nos leva a perceber que somos sujeitos produzidos, produzidos nas instituições tanto de educação e saúde onde quem usa branco já sinaliza que é aquele que ensina, o que determina, e, portanto, é aquele que fala. $O$ outro ouve e até se sente acanhado de falar o que realmente está se passando, ou então, já incorporou que nos serviços de saúde só se deve falar de desajustes do corpo anatômico, falando somente aquilo que a enfermeira ou o médico quer ouvir. "Estou dando direitinho o peito, estou dando papinha." Portanto, este conceito foi produzido no modo de conceber saúde e este modo também produz este conceito.

Campos (1997) aborda o grau de alienação dos trabalhadores, que varia de acordo com a circunstância do contexto e de sua própria atuação em relação ao objetivo, objeto e meios de trabalho dos serviços de saúde e defende a identidade do trabalhador comprometida com a produção de saúde em defesa da vida e não uma "identidade assegurada mais pelo diploma, pelo uniforme branco da indiferença e pelo fechamento dos seus saberes ao comum dos leigos" (p.242).

Nesse espaço de relações reveladas de objetividade oculta-se a produção de subjetividades. Esta é a dimensão que os trabalhadores afirmam estarem desenvolvendo na assistência domiciliar. Mencionam que esta prática os faz sentirem-se como estranhos, o que nos leva a pensar que os mecanismos de defesa, os espaços de segurança utilizados no hospital, nas UBSs e a construção da identidade, caracterizados pelos valores citados, começam a ser "tocados", revistos. É o início de um mergulho na tentativa de enfrentar o desconhecido e também a aproximação com o sentimento de frustração, de angústia para, posteriormente, desfrutar o prazer de se ver diante de um "mar de possibilidades".

Para os institucionalistas o desconhecido é perigoso, podendo provocar desorganização nas defesas, o que nos leva a pensar que muitos trabalhadores podem não estar dispostos a enfrentar as dores inevitáveis desse mergulho fora do seu espaço de segurança.

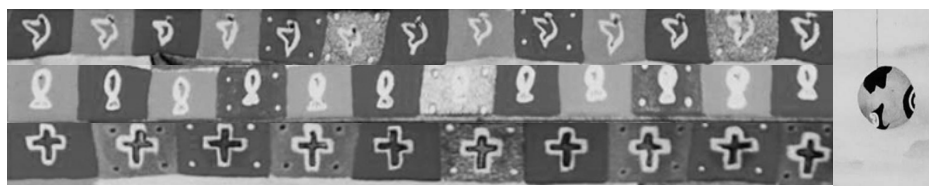

Interface - Comunic, Saúde, Educ, v7, n12, p.83-100, fev 2003 
Por vezes, enganamo-nos no cotidiano dos serviços de saúde, pois o trabalho ali desenvolvido é e está sujeito a imprevistos. Campos (1997, p.229) faz essa consideração da imprevisibilidade, lembrando, por exemplo, "com alguma razão na clínica 'cada caso é um caso"”. Não estamos negando as tendências, as regularidades, mas tentando dizer que, por mais que nos sintamos seguros com as normas, com as rotinas e com o acúmulo de experiências, estamos sempre expostos a imprevistos; portanto, temos a ilusão de segurança.

Ao nos permitirmos enfrentar a angústia do novo temos oportunidade de aprender, de descobrir outros valores, outros mundos, de reincorporar o "ser humano" no processo do cuidado, uma vez que em determinados tempos/espaços, esse ser, em nome da pretensa objetividade, foi ou é discriminado.

O processo de trabalho em saúde não pode ser restrito aos extremos, daquele que supostamente "atende" e do que é supostamente "atendido". Entre o trabalhador e o usuário permeia uma rede de relações, próprias daquele momento, composta também de outras relações que se desenvolvem não só entre eles, mas criada a partir da rede de relações próprias de cada um, havendo, às vezes, distintos pontos de convergência. Essas teias produzidas na sociedade em que vivem é determinada $e$ determina um modo de produção, e tem na sua produção também bens de relações traduzidos por costumes, crenças, sentimentos, valores, enfim um modo de "andar" na vida, o qual pode se cristalizar ou se modificar.

As enfermeiras demonstram aproximar desta compreensão ao declararem como vêm processando as experiências oportunizadas pela assistência domiciliar:

[...]. Eu acho que não saberia pontuar se foi a partir da visita ou não, mas eu vejo que a gente passou por um processo de enxergar as coisas de um modo diferente [...]. Isso vem acontecendo, acho que hoje trabalho de um modo diferente do que era há dez anos atrás. Acho que tem a ver com você sair, ver o paciente de uma outra forma. Essa visita a gente valoriza principalmente quando vai até bolsões mesmo de pobreza, eu acho que quando a gente faz sente o impacto da vida que valoriza muito [...], tem muita coisa que a gente não valoriza $e$ que a partir do momento que você vai, vê, olha, a gente passa a valorizar $e$ a ter outros valores que às vezes passariam desapercebidos. Isso deu um impacto na minha vida profissional sim, da forma que eu olho o paciente, que eu atendo [...]. (DSC)

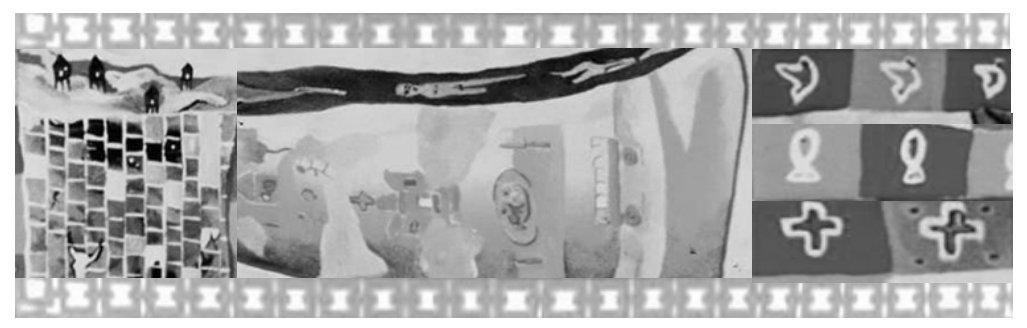


Esta situação retrata o trabalhador como homem histórico e social, que modifica a si mesmo, o meio e o outro no processo das relações sociais. Ele se abre para a relação de alteridade, ou seja, vê o outro, um diferente, o que o faz rever suas concepções, seus valores, enfim sua prática. É o reconhecimento da diferença entre ele e o outro, e esta dimensão da relação é importante passo na sensibilização para o desenvolvimento de um projeto de trabalho no eixo da defesa da vida e da cidadania. Isso deu um impacto na minha vida profissional sim, da forma que eu olho o paciente, que eu atendo.

Podemos ainda perceber o quanto se faz necessário reconhecer o saber do outro, mesmo que isso, a princípio, signifique abandonar o marco de segurança, causando medo e temor de enfrentar as ansiedades. Enfrentar esses desafios abre possibilidades de aprendizagem, de mudanças nas nossas atitudes e no nosso modo de olhar o outro. Para Bleger $(1989$, p.65), "Ansiedades e confusões são, por outro lado, ineludíveis no processo do pensar e, portanto, da aprendizagem", constituindo momentos do processo criador.

A assistência domiciliar aparece mais uma vez com potência proporcionando uma outra leitura da realidade, o desenvolvimento da capacidade crítica, assim como uma releitura das intervenções realizadas cotidianamente nos serviços de saúde. A assistência domiciliar favorece, também, sentimentos de solidariedade relacionados à dor $e$ ao sofrimento do outro, que não são exclusividade apenas desse processo. Ao sairmos dos serviços de saúde para o domicílio, já existe a permissão para enfrentarmos esse desafio, para tentarmos romper o medo e, até, para arriscarmos viver a contradição sofrimento/satisfação, anunciando, assim, que a assistência domiciliar pode ser um disparador para o repensar do processo saúdedoença-cuidado.

Sá (2001), estudando os fenômenos de desvalorização da vida, de banalização da dor e dos sofrimentos alheios no processo de trabalho em saúde, afirma ser a própria natureza do trabalho em saúde uma atividade ansiogênica $e$, portanto, produtora de defesas. Uma das defesas está na forma como se dá o processo de trabalho, segmentado e descontínuo, impossibilitando "muitos trabalhadores de saúde se solidarizarem com a dor e o sofrimento alheios” (p.154). Isabel Menzies (1970 apud Sá, 2001), discute a natureza específica da ansiedade no trabalho da Enfermagem, apontando que o mesmo "suscita sentimentos muito fortes $e$ contraditórios" na enfermeira (p.155). Seguindo, a autora menciona que as técnicas de defesa desenvolvidas em conseqüência dessa situação estão ligadas ao modo de organização do trabalho, à divisão técnica mediante a qual cada trabalhador faz determinados procedimentos, evitando entrar em contato de forma integral com o paciente; da despersonalização ou negação das diferenças individuais, quando identificam os pacientes por suas patologias, pelo número do leito ou número da família; da obscuridade intencional na distribuição de responsabilidade, quando não se tem claro quem é responsável pelo que e por quem e ainda pela resistência à mudança.

As enfermeiras participantes desta investigação relatam que a vivência no $S A D$ tem possibilitado a produção de sentimentos de natureza diferente daqueles encontrados por Menzies. 
PEREIRA, M. J. B., MISHIMA, S. M.

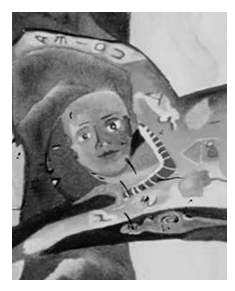

[...] conhecer a situação das pessoas que freqüentam a sua unidade, porque lá dentro eles podem se apresentar de uma maneira [...] lá fora de outra, é aquela história, você vai num posto, num hospital, põe a melhor roupa e o paciente fala aquilo que a enfermeira ou o médico quer ouvir. [...] se depara com aquilo, que pára de falar um pouquinho, escuta e vê [...], você vê a diferença que faz algumas coisas, além de você ver e orientar no posto, no hospital $e$ ir lá [...]. Conhecer o lado de lá [...], tem muita coisa que a gente não valoriza e que a partir do momento que você vai, vê, olha, a gente passa a valorizar e a ter outros valores que as vezes passariam desapercebidos. (DSC)

Observando as produções subjetivas que o processo de trabalho do SAD tem possibilitado aos trabalhadores, inclusive assinalando um afastamento dos apontados por Menzies (apud Sá, 2001), trazemos o fragmento:

\footnotetext{
Admito que eu fiz muita visita errada, e como! De você dar a receitinha pronta, de estar curando o umbigo com éter? A mãe respondia: 'ah, estou pondo isto, ah!' e você afirmava que tinha que colocar o éter, daquela maneira incisiva. E não buscava a cultura porque ela pôs isso ou aquilo. [...] Não é do jeito que eu quero, redondinho, bonitinho e de reflexão da gente enquanto pessoa, enquanto profissional possibilita isso pra gente. É muito risco enquanto experiência de vida, vi o outro lado da assistência, foi muito rico. Você fica preocupada porque quando a gente não vê a gente não sente, é diferente. É um trabalho que a gente sempre tem que aceitar ser revisto. (DSC)
}

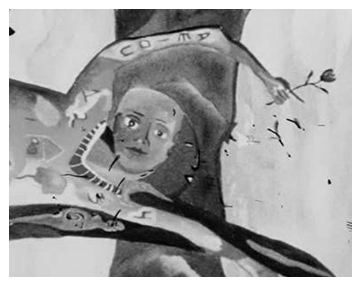

As participantes deste estudo relatam que ir até o domicílio do paciente provoca uma série de revisões, indicando, inicialmente, deslocamento do processo de resistência com vistas à mudança. Reconhecer o que se fez $e$ depois ter a possibilidade de concluir que aquela não foi a forma mais adequada, e que tanto o usuário como sua família poderiam ser mais bem atendidos não é comum, uma vez que isso pressupõe abandonar a atitude onipotente que conformamos nas nossas relações. Contudo, é necessário sempre termos em mente o motivo pelo qual e para quê estamos nos serviços de saúde, e o nosso trabalho deve ser direcionado, pois afinal qual é a finalidade do trabalho em saúde?

As enfermeiras demonstram estar tendo um outro entendimento da finalidade do seu trabalho, quando manifestam ser ilusão considerar que uma parte do processo de trabalho foi cumprida.

[...] mesmo que muitas vezes a sensação de impotência seja tão grande que você sai muitas vezes frustrada e volta pra unidade arrasada. Às vezes a situação é tão deprimente [...] que você fala: "Eu não deveria nem ter saído" [..] mas você aprende muito com o paciente, e com as situações que você vê. É um trabalho que a gente sempre tem que aceitar ser revisto. 
Percebemos que, ao se afastarem desta concepção, estão vislumbrando o caminho da co-responsabilidade pela saúde do outro, que exige entendimento do processo de aprendizagem, revisão que também provoca desorganização nas defesas, insegurança, ansiedade, angústia e sofrimento na ação.

Ao adotar essa perspectiva fica subentendida uma possibilidade de modificação na relação de poder entre trabalhador e usuário, que pode ser um dos pontos-chave da resistência pois, para processar essa transformação, pressupõe-se a coexistência - ou pelo menos a alternância - de ansiedades distintas, uma denominada paranóide representada pela ameaça do novo, do desconhecido, $e$ a ansiedade depressiva que se manifesta pela "perda de um esquema referencial e de um certo vínculo que a aprendizagem sempre envolve" (Bleger, 1989, p.72). Nesse movimento vamos experimentando a insuficiência do saber estruturado no conhecimento do corpo anátomofisiológico, sem contudo negarmos sua importância e necessidade, evidenciando que só as tecnologias leve-duras e duras não são suficientes no trato da complexidade das relações que envolvem o processo saúde-doençacuidado. Desse modo, as diferenças individuais, as crenças e os aspectos culturais passam a ser considerados neste processo de trabalho.

A todo momento, no transcorrer da pesquisa, identificamos fatos da subjetividade imanentes a todo processo de trabalho. Guattari e Rolnik (1996, p.33) afirmam que "a subjetividade está em circulação nos conjuntos sociais de diferentes tamanhos: ela é essencialmente social, e assumida e vivida por indivíduos em suas existências particulares”. Os autores mostram a oscilação pendular que os indivíduos podem viver, ou seja, do pólo da alienação/opressão à singularização. Referem que na subjetividade relativa à alienação/opressão, o indivíduo se modela e se submete à subjetividade recebida, enquanto na subjetividade singular ele se reapropria dos componentes da singularidade recebida num processo de reelaboração, criação e constituição que compõe as instâncias de manutenção e as de transformação.

Entre o explícito e o oculto: a (re)construção das relações entre trabalhadores e usuários

As enfermeiras do SAD apresentam em seus depoimentos o estabelecimento de envolvimento mais personalizado, que vai além da realização do procedimento técnico; falam de conhecer o paciente; das possibilidades de seguimento; da criação de um outro envolvimento com vínculo, empatia, auto-confiança, solidariedade, elementos explícitos nos fragmentos a seguir, afastando-se, assim, dos mecanismos de defesa referidos por Menzies (apud Sá, 2001):

[...] no domicílio a gente pode ir muito além, não pode ficar só na história que a gente vai fazer um curativo, pude perceber isto [...] e é fundamental. [...] Quando você faz assistência domiciliar, você passa a conhecer o paciente, cria um outro vínculo, um outro envolvimento. Aí a gente não quer abrir mão também, porque o envolvimento, o vínculo é diferente. Isto não é exclusivo 


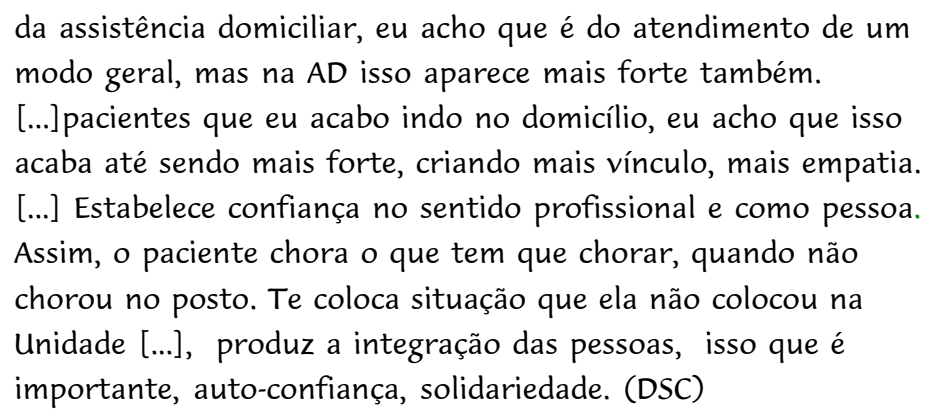

Nesses fragmentos, as agentes da investigação afirmam que os encontros no domicílio entre trabalhadores e usuários têm permitido a revelação de fatos que, no cotidiano dos serviços de saúde, costumeiramente são ocultados. Muitas vezes até encontram explicações objetivas para (re) significação desse encontro, como no fragmento a seguir:

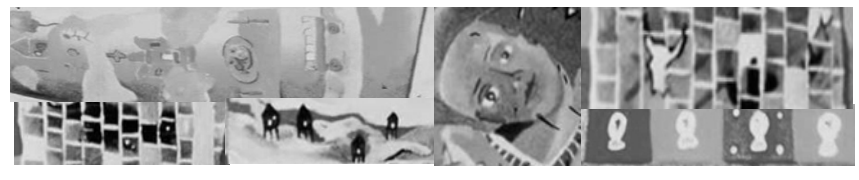

O domicílio também pode ser um espaço de abertura. Os dois (trabalhador e usuário) podem estar disponíveis, porque ali ninguém está te telefonando, ninguém está te chamando pra fazer outra coisa [...]. (DSC)

A ausência dos ruídos externos pode significar a passagem, ou a abertura para a manifestação dos ruídos internos, ou seja, o padrão de comportamento que está na base das relações pode estar se ampliando e não se reduzindo estritamente aos alicerces biomédicos permitindo, assim, uma relação que

[...] produz a integração das pessoas, isso que é importante, autoconfiança, solidariedade...[...] mas, nos pacientes que eu acabo indo no domicílio, eu acho que isso acaba até sendo mais forte, criando mais vínculo, mais empatia. (DSC)

Os espaços dos serviços de saúde e do domicílio parecem ser paradoxais ao se apresentarem com possibilidades semelhantes, porém são reconhecidos com significações antagônicas, pois na unidade de saúde o lugar de espera e a demora são "insustentáveis".

Quando na unidade você pára para ouvir o usuário colocar suas dificuldades, o marido não entende, faz cara feia, tá na hora do futebol, o serviço está demorando e quer que ela vá embora. Aí é necessário conversar com ele para esperar [...]. (DSC)

Ao procurar o serviço de saúde, o usuário busca satisfazer algum tipo de necessidade, mais imediato, voltado à saúde; no entanto, no espaço domiciliar, o tempo se apresenta mais "largo" e maior é o grau de tolerância na espera. A demora aqui parece ser bem vinda e constitui um dos fios para 
tecer as possibilidades ocultadas na unidade

O domicílio também pode ser um espaço de abertura.[...] Assim o paciente chora o que tem que chorar, quando não chorou no posto. Te coloca a situação que ela não colocou na Unidade [...]. (DSC)

A assistência domiciliar é revelada pelos trabalhadores como potencialidade para rever o significado das tecnologias utilizadas no cuidado, ou mesmo a sua prática profissional. No modelo de saúde hegemônico, as tecnologias predominantes no processo de trabalho são as duras e leve-duras, sendo as leves discretamente ou quase nunca utilizadas. No domicílio, as tecnologias leves parecem emergir com maior visibilidade e necessidade, provocando insegurança, medo de estar fazendo tudo errado, e de estar se desviando da assistência, conforme manifestações traduzidas pelas enfermeiras:

${ }^{5} \mathrm{O}$ termo adesão tem por referência a dificuldade do paciente aceitar o tratamento prescrito, principalmente com relação a uso de medicamentos ou outra ação terapêutica proposta. então nesse tipo de trabalho eu fui me desviando muito da parte de assistência só de procedimento técnico, e comecei a visitar... muita adesão, e nessa adesão ${ }^{5}$ u achei que estava fazendo tudo errado, eu falava: tá tudo errado [...]. (DSC)

A prática de Enfermagem, neste fragmento, é reconhecida predominantemente pelo saber/fazer de procedimentos técnicos tecnologias leve-duras e duras, sendo as leves negadas e até mesmo consideradas equivocadas/errôneas. Ao tentarmos analisar sob a dimensão subjetiva, o afastamento dos procedimentos técnicos tem implicações no território das perdas (não estou fazendo aquilo que é meu, que faz parte do meu saber/fazer, aquilo que é do meu domínio) e também porque o que normalmente não era e/ou é valorizado - as tecnologias leves - significam caminhar por outros espaços que também amedrontam, é o novo, e por não se ter o domínio, as defesas frente a possíveis ataques são muito lábeis e o medo do ataque se destaca. Normalmente, é mais fácil achar que está tudo errado e não enfrentar a situação, mas felizmente não foi esse o caminho tomado pelas agentes deste estudo, que demonstraram estar caminhando em direção a mudanças, procurando incorporar o invisível que está nas entranhas do visível, que pode ser escutado e enxergado não só pelo trabalhador como também pelo usuário.

Isso deu uma diminuída, não acho as técnicas, mas dentro daquela situação você também sempre fez alguma coisa, porque mesmo que você sai e diz 'eu não fiz nada', daí uns dias você encontra a pessoa e ela diz que você fez um monte de coisas, então o retorno não é de caso por caso, o retorno é como um contexto, às vezes você não fez nada mesmo de técnica, mas você conversou, deu atenção, nós vamos mudar uma estória [...]. (DSC) 
Merhy (1998) fala da importância de a Enfermagem retomar o núcleo de competência que lhe cabe, enquanto ação cuidadora, detendo-se no doente $e$ não na doença. Ao se voltar para o doente, parece que se constitui o núcleo de competência da Enfermagem mediante a interação $e$ a intervenção, para o cuidado se processar. Neste sentido, os procedimentos técnicos fazem parte de seu núcleo de competência, porém a Enfermagem deve estar alerta para não reduzir o seu núcleo a esta ação apenas, ou seja, aos

procedimentos. Deve procurar desenvolvê-los na perspectiva de aproveitar o espaço existente, para estabelecer diálogos valorizando a fala e a escuta, os anseios, as angústias e as expectativas dos usuários, buscando ações intercomplementares entre as equipes de saúde e outras, entre os usuários $e$ a sociedade, visando ao desenvolvimento do processo de tomada de consciência de seus direitos de cidadão, e a sua emancipação. De certa forma, as enfermeiras que atuam no SAD expressam esta dimensão cuidadora ampliada, sem contudo visualizarem o direito de cidadão e da emancipação do usuário.

As contradições - tempo no espaço domiciliar e falta de tempo no espaço dos serviços de saúde; harmonia entre ociosidade e excesso de demanda; procedimento técnico significando assistência e não assistência - articuladas às justificativas para se estabelecer uma relação entre trabalhador e usuário qualificada de forma diferenciada (o vínculo é diferente, auto-confiança, solidariedade) são temas a serem discutidos em espaços coletivos.

Esta perspectiva mais integradora vem sendo evidenciada em diversas oportunidades, pelas enfermeiras, ao reconhecerem a trama do processo saúde-doença-cuidado dentro do contexto sócio-econômico, e que não bastam prescrições de condutas pautadas pelo saber técnico. Vai se fazendo presente um movimento que aponta para a necessidade de reconstruírmos a assistência a partir da recomposição deste saber técnico com um outro "saber" que considere as distintas dimensões presentes no cuidado.

Esta perspectiva horizontalizada na relação ensino-aprendizagem é explicitada quando valorizamos a importância de saber/fazer procedimentos técnicos, principalmente nas ações relativas a doenças transmissíveis. Tal habilidade refere-se à "segurança" obtida na vivência hospitalar, ou seja, não valorizamos num dado momento apenas uma tecnologia e num outro momento a desprezamos pela valorização de outra. Ao contrário, as enfermeiras explicitam que, mediante um procedimento técnico, podem aliviar o medo dos familiares em manipular secreções e excreções que significam riscos de contaminação, situação que tem sido o veículo para o estabelecimento de "vínculos, de formar laços".

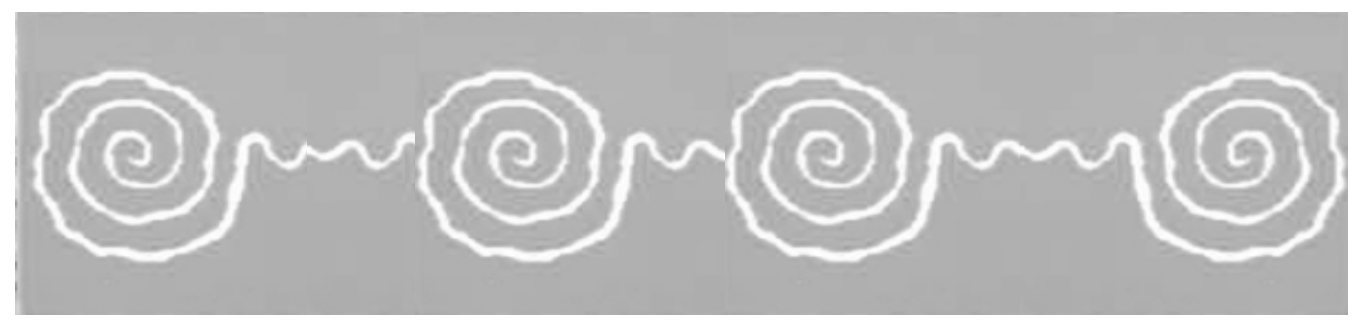


Estabelecendo o vínculo possível: um dispositivo para revisão do processo de trabalho

Quando as enfermeiras falam de vínculo, identificamos a necessidade da construção de uma concepção do trabalho em saúde em que a sensibilização pelas dificuldades e sofrimentos do outro seja considerada como aspecto relevante para a equipe de saúde. Isto implica "refletir sobre a responsabilidade e o compromisso que a equipe tem com cada usuário de sua área de abrangência e com os tipos de problema que eles apresentam" (Merhy, 1994, p.138). Para abordar o vínculo nos apoiaremos em PichonRivière (apud Adamson, 2001, p.3), que assim o define:

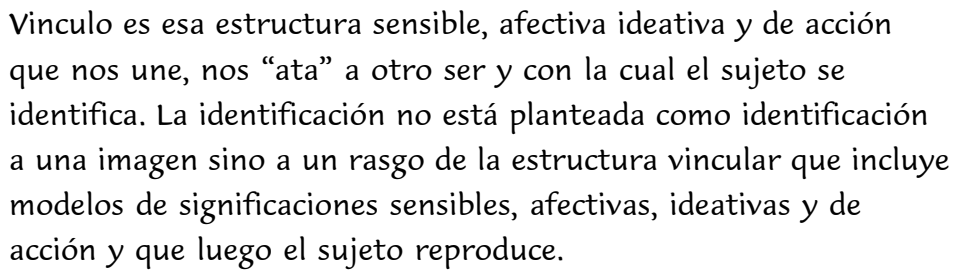

No modelo atual hegemônico não temos o traço da estrutura vincular que dimensiona a sensibilidade, os afetos, como vicissitudes conformadoras das ações de saúde e, portanto, a sensibilidade não pode ser reproduzida, significando que sua dimensão precisa ser construída nas ações de saúde. Precisamos exercitá-la, já que esta dimensão existe e quando falamos sobre a necessidade de sua construção não estamos dizendo que partiremos do zero, pois é nossa intenção adotar outros conceitos, como por exemplo, o de esquema referencial, "el conjunto de conocimiento, de actitudes que cada uno de nosotros tiene en su mente y con el cual trabaja en relación con o mundo y consigo mismo" (Adamson, 2001, p.3).

Esta afirmação pressupõe a preexistência, em cada um de nós, de um esquema referencial construído nas diversas e complexas relações que vamos estabelecendo por "onde andamos a vida". Essas relações vão conformando um conjunto de conhecimentos, de experiências, provocando afetos/ desafetos e é com essa bagagem que os indivíduos pensam e agem.

Adamson (2001, p.4) afirma que "este esquema referencial es que le permite al sujeto poseer modelos de sensibilidad, modos de pensar, sentir $y$ hacer no el mundo que marcan su cuerpo de determinada manera". Neste sentido, a autora explica a tendência à reprodução e resistência a idéias novas que representem tendência à desestruturação.

Estes conceitos são importantes para entendermos que a subjetividade é construída socialmente, permitindo que olhemos tanto para o trabalhador de saúde como para o usuário, como seres que conformam um esquema referencial construído em suas relações. Esta idéia mostra que suas atitudes representam os vínculos por eles estabelecidos nas diferentes experiências $e$ fases da vida, o que nos permite dizer que vínculo é uma estrutura com dupla face - uma interna e outra externa. Esclarecendo ainda mais essa complexidade, Pichon-Rivière (apud Adamson, 2001, p.3) refere-se à

subjetividade como uma "verdadera selva de vínculos".

No cotidiano dos serviços de saúde, estas relações acontecem 
permanentemente e, de modo geral, são tomadas de forma pessoal, conformando uma imagem, a qual é muito bem explicitada por Mishima $(2001)^{6}$ :

Os trabalhadores em sua relação com os usuários estão uns para os outros e uns com os outros cristalizados e "prontos", não se percebem sendo conformados nestas relações e protagonistas delas, e se conformam: não temos saídas, "sinceramente não tem solução".

${ }^{6}$ Palestra proferida na I Conferência Regional de Saúde Mental da DIR XVIII, na cidade de Ribeirão Preto, em setembro de 2001

As enfermeiras revelam acreditar, ou pelo menos tentam se aproximar de saídas, mesmo que em muitos momentos as dificuldades transpareçam como indicadores de desânimo. No entanto, parecem ousar e enfrentar o desconhecido. Esta leitura é feita pela (re)significação de conceitos e/ou experiências acumuladas, quando estas agentes declaram:

\begin{abstract}
Quando você faz assistência domiciliar, você passa a conhecer o paciente, cria um outro vínculo, um outro envolvimento. Aí a gente não quer abrir mão também, porque o envolvimento, o vínculo é diferente. Isto não é exclusivo da assistência domiciliar, eu acho que é do atendimento de um modo geral, mas na $A D$ isso aparece mais forte também. Não tenho vergonha, eu me pego muito, marcando retorno pro paciente, orientando: “ah! Você vem tal dia, que eu vou estar aqui de tarde. Você me procura”. (DSC)
\end{abstract}

A assistência domiciliar tem possibilitado a conformação do modo de (re) pensar, de sentir e, portanto, de agir, configurando-se num modelo de sensibilidade, com características que não estão pautadas apenas em indicadores biológicos, mas em outros, como por exemplo, a enfermeira quer continuar a ver, a escutar, e a saber o que está acontecendo com o usuário, demonstrando estar se aproximando de um cuidar que traduz preocupação com o outro, solidariedade e responsabilidade, condizendo com o que diz Pessini (2000, p.236): "Cuidar, mais que um ato isolado, é uma atitude constante de ocupação, preocupação, de responsabilização e de envolvimento de ternura com o semelhante".

Segundo Merhy (1998), esse jeito de cuidar é apontado como uma forma de atender parte das necessidades dos usuários e afirma

\footnotetext{
do ponto de vista do usuário [...] em geral, este não reclama da falta de conhecimento tecnológico no seu atendimento, mas sim da falta de interesse e de responsabilização dos diferentes serviços em torno de si e de seu problema. (Merhy, 1998, p.2)
}

Esta forma de produção, ou seja, o agir em saúde que vem se estabelecendo nas relações experimentadas por essas agentes, só pôde ser construída $e$ vivida porque o pólo da resistência não permaneceu sobreposto ao pólo da mudança. Um outro fato que contribui para isso é de terem vivenciado a exposição de sentimentos fortes e contraditórios que a assistência domiciliar 


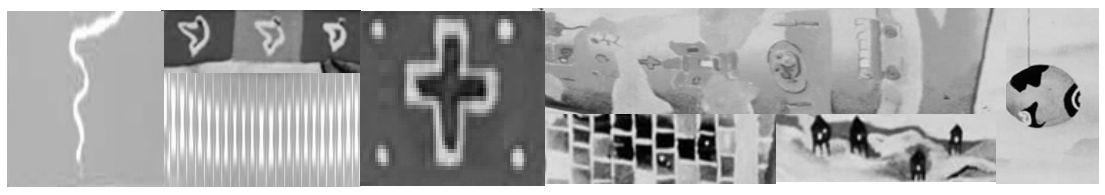

poderia/pode suscitar, como por exemplo, medo de não dar conta; de estar só; de tomar decisões que podem não dar certo; de ter que dizer "não sei"; sentir-se impotente; de reconhecer que os trabalhadores da saúde não dão conta de resolver os problemas de saúde dentro de uma concepção ampliada do processo saúde/doença; destes se identificarem com situações semelhantes às de sua vida e de seus familiares. Portanto, não se apoiando em motivos que justificariam objetivamente a negação para assumirem a assistência domiciliar estariam "camuflando" outras razões que, por não serem suficientemente conhecidas e discutidas, não permitiriam decisões apoiadas em razões claras e conscientes.

Enfrentar essas situações possibilitará reconhecer que riscos e conquistas, angústias e alegrias, prazeres e desprazeres poderão estar presentes no processo e que, muitas vezes, as enfermeiras precisarão de suporte para ajudá-las a rever suas decisões, principalmente porque mudanças $e$ criatividade são revestidas de dor e satisfação.

Decidir pela manutenção da situação também implica pensar que esta decisão se relaciona a dificuldades externas e também às do próprio indivíduo, que, por avaliar as dificuldades de enfrentar os riscos de desestruturação naquele espaço e tempo, opta por manter aquilo que é conhecido, que está mais estabelecido.

Queremos esclarecer que não estamos qualificando a decisão de mudar ou de permanecer como boa ou ruim, respectivamente, mas ressaltamos que qualquer que seja a decisão, ela precisa ser desvendada nas suas múltiplas facetas. Então consideramos que há potencialidade para que os esquemas referenciais também se estruturem e se modifiquem, de forma que os trabalhadores se considerem protagonistas das diferentes conformações que vão sendo estabelecidas nos serviços de saúde, e oxalá os usuários possam sentir o mesmo, por serem os obstáculos e os limites inerentes a todo caminhar e ainda esses obstáculos. Ainda é nosso desejo que obstáculos e limites possam ser apreendidos como disparadores com possibilidades de revisão e de retomada, acreditando na criatividade quando se tem um projeto na vida.

Esta direção foi reconhecida pelas agentes deste estudo, quando se referem ao processo de mudança que vem ocorrendo na Secretaria Municipal da Saúde.

[...] Eu não saberia precisar, a partir da visita ou sem visita, mas eu acho que tem hoje com essa discussão ao longo desses últimos anos, que tem a ver com a inclusão da visita domiciliar, então, eu relaciono, porque a partir do momento que a gente passou a discutir o processo da visita domiciliar na própria Secretaria, eu acho eu tem a ver com isso, toda essa mudança de olhar. (DSC) 
Produzindo subjetividades e possibilidades de (re) criação do trabalho em saúde: utopia possível??

Nesse emaranhado de cuidados, dúvidas e desafios, tivemos, por parte das integrantes deste estudo, a revelação de situações que exigem um novo modo de agir nos serviços de saúde, que promovem vínculos de afeto e de confiança que passam a ter um significado de conquista, "de oxigênio" para o trabalho.

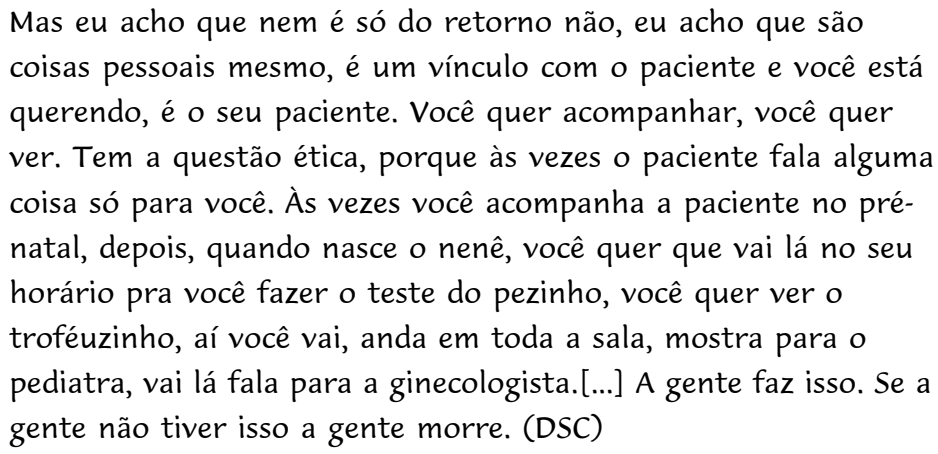

Este fragmento de depoimento mostra aproximação do caráter humano da relação entre os homens, evidenciando que ambos, enfermeira e usuários, portam alguma necessidade que precisa ser satisfeita e que no trabalho em saúde os trabalhadores "podem através de suas habilidades e conhecimentos específicos, possibilitar a satisfação de parte destas necessidade" (Mishima et al., 1998, p.180).

Analisando ainda o fragmento anterior, vemos que as enfermeiras tratam do monitoramento desenvolvido pelo conjunto dos trabalhadores da unidade de saúde, por ocasião do período gravídico-puerperal pelo menos do binômio mãe-filho, conforme explicitado por elas, o que pressupõe um saber/fazer que requer uma série de tecnologias - duras, leve-duras e leves. As agentes deste estudo destacaram as tecnologias de natureza leve, como sentimentos, afetos, significados demonstrando, enfim, as relações entre os homens. Assim, no nosso dia a dia, estamos produzindo objetiva $e$ subjetivamente saúde/doença:

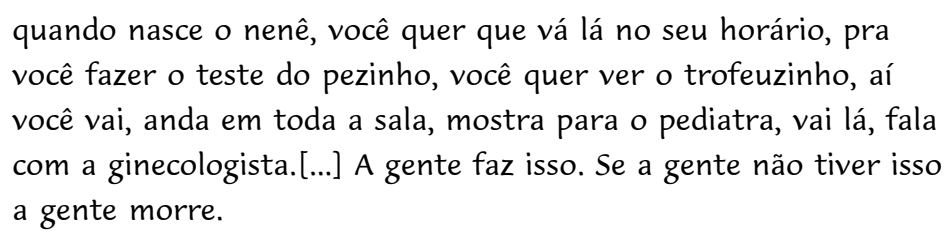

Este depoimento ressalta que a expressão da subjetividade pode ser evidenciada como o modo de lidar com o outro e a manifestação de estar alegre, animado. Mediante esses pequenos/grandes gestos vamos mostrando nosso jeito de ser, produzindo e modelando a subjetividade, e no trabalho em saúde, particularmente no cotidiano da Enfermagem, ao fazermos nossas ações também estamos sendo feitos por elas. Quando as relações são estabelecidas de forma a possibilitar compartilhar o sofrimento, a dor, a 
alegria e os prazeres, aumentam as chances da produção de um outro "fazer em saúde", procurando dar mais vida a quem busca e a quem trabalha na saúde.

Campos (1994, p.61) compara a organização dos serviços públicos de Saúde a "[...] pesadas pirâmides, que esmagam com seu peso as necessidades expressas pela demanda por atenção e as possibilidades de agir criativo dos profissionais [...]" e ainda propõe

a substituição da pirâmide por um redemoinho de ponta-cabeças. Micro-furacões com a base em movimento sobre o solo. Ao invés de uma estrutura ossificada pelo concreto das normas e programas, um fluxo cuja velocidade, disposição, fossem governadas pelo tal modelo. Um tufão invertido e em movimento, tendo como fonte de energia as necessidades e interesses dos usuários e como leme o diálogo do saber técnico com este torvelinho de desejos. (Campos, 1994, p.61)

Acompanhando a ordenação dos dados temos, em diferentes momentos e situações, expressões comprometidas com uma prática de saúde/enfermagem voltada para relações de responsabilização, vínculo e prática humanizada. Nessas experiências precisamos encontrar lacunas que possibilitem a criação de um espaço coletivo de trabalho, onde, constantemente, seja questionado o instituído, os determinantes internos e externos do contexto em que se desenvolve o trabalho em saúde, exercitando o pensar crítico dos espaços institucionais. Além disso, devemos prever as resistências às mudanças, para construção de forma prática e operacional de um projeto de saúde em que os trabalhadores se sintam co-responsáveis, o prazer se manifeste em decorrência da realização do trabalho e das reflexões geradas nesse processo, e, também, a angústia seja produto inerente à criatividade e ao processo de revisão constante.

\section{Referências}

ADAMSON, L.G. Concepción de subjetividade en E. P. Rivière. Disponível em: <http:// www.geocities.com/athens/forvn/5396/subjetividad.html> acesso em 03/10/2001.

ALMEIDA, M.C.P. $O$ trabalho de enfermagem e sua articulação com o processo de trabalho em saúde coletiva: rede básica de saúde em Ribeirão Preto. Ribeirão Preto, 1991. Tese (Livre Docência) Escola de Enfermagem de Ribeirão Preto, Universidade de São Paulo.

BAREMBLITT, G.F. Compêndio de análise institucional e outras correntes: teoria e prática. 2.ed. Rio de Janeiro: Rosa dos Tempos, 1994.

BAZ, M., BARRIGA, A.D. Concepción operativa de grupo e investigación. Su ubicación en el contexto de las ciências sociales. In: BAZ, M., CAPARRÓS, N., DE BRASI, J.C., BARRIGA, A. D., EVANS, S., FERNANDEZ, A.M., HERRERA, L., KESSELMAN, H., PAVLOVSKY, C., PAVLOVSKY, E., PERCIA, M., SAIDÓN, O., SMOLOVICH, R. (Orgs.) Lo grupal 9. Argentina: Ediciones Busqueda de AYLLU S.R.L., 1991. p.115-43.

BLEGER, J. Grupos operativos no ensino. In: BLEGER, J. Temas de Psicologia: entrevista e grupo. 4.ed. São Paulo: Martins Fontes, 1989. p.53-82.

CAMPOS, G.W.S. Considerações sobre a arte e a ciência da mudança: revolução das coisas e reforma das pessoas. O caso da saúde. In: OLIVEIRA, L.C. (Org.) Inventando a mudança na saúde. São Paulo: Hucitec, 1994. p.29-87.

CAMPOS, G.W.S. Subjetividade e administração de pessoal: considerações sobre modos de gerenciar o trabalho em equipes de saúde: In: MEHRY, E.E, ONOKO, R. (Orgs.) Agir em saúde: um desafio para o 
PEREIRA, M. J. B., MISHIMA, S. M.

público. São Paulo: Hucitec, 1997. p.229-66.

GUATARRI, F., ROLNIK, S. Micropolítica, cartografia do desejo. 4.ed. Petrópolis: Vozes, 1996.

LEFÉVRE, F., LEFÉVRE, A.M.C., TEIXEIRA, J.J.V. O discurso do sujeito coletivo. Uma nova abordagem metodológica em pesquisa qualitativa. Caxias do Sul: EDUCS, 2000.

MERHY, E. E. Em busca da qualidade serviços de saúde: os serviços de porta aberta para a saúde e o modelo tecno-assistencial em defesa da vida (ou como aproveitar os ruídos do cotidiano dos serviços de saúde e colegiadamente reorganizar o processo de trabalho na busca da qualidade das ações de saúde. In: OLIVEIRA, L.C. (Org.) Inventando a mudança na saúde. São Paulo: Hucitec, 1994. p.117-60.

MERHY, E.E. A perda da dimensão cuidadora na produção da saúde - uma discussão do modelo assistencial e da intervenção no seu modo de trabalhar a assistência. In: REIS, A.T., SANTOS, A. F., CAMPOS, C.R., MALTA, D.C., MERHY, E.E. (Orgs.) Sistema Único de Saúde em Belo Horizonte: reescrevendo o público. São Paulo: Xamã, 1998. p.103-20. parte II.

MERHY, E.E., CHAKKOUR, M., STÉFANO, E., STÉFANO, M.E., SANTOS, C.M., RODRIGUES, R.A., OLIVEIRA, P. C. P. Em busca de ferramentas analisadoras das tecnologias em saúde: a informação e o dia a dia de um serviço, interrogando e gerindo trabalho em saúde. In: MERHY, E.E., ONOCKO, R. (Orgs.) Agir em saúde. Ủm desafio para o público. São Paulo: Hucitec, 1997. p.113-50.

MISHIMA, S.M., ALMEIDA, M.C.P., PINTO, I.C., VILLA, T.C.S., ANSELMI, M. L. Reflexões acerca da gerência do cuidado de enfermagem na rede básica de saúde. In: CONGRESSO BRASILEIRO DE ENFERMAGEM, 50, 1998. Salvador. Anais... Salvador, 1998. p.180.

MISHIMA, S.M. Cuidar sim. Excluir NÃO!! - Algumas reflexões sobre a questão dos Recursos Humanos Palestra proferida na I Conferência Regional de Saúde Mental da DIR XVIII, na cidade de Ribeirão Preto, em setembro de 2001.

MORGAN, D.L. Focus groups as qualitative research. 2.ed. Thousand Oaksi: Sage Publications, 1997. PESSINI, L. O cuidado em saúde. O mundo da saúde, v.24, n.4, p.235-236, 2000.

SÁ, M.C. Subjetividade e projetos coletivos: mal-estar e governabilidade nas organizações de saúde. Cienc Saúde Colet., v.6, n.1, p.151-64, 2001.

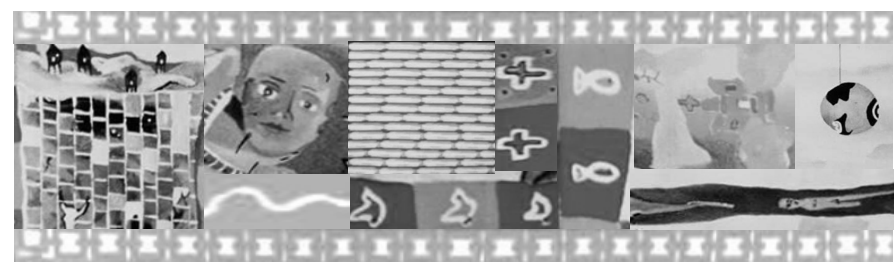

PEREIRA, M.J.B., MISHIMA, S.M. Revisitando la práctica asistencial: la subjetividad como materia para la reorganización del proceso de trabajo en enfermería, Interface - Comunic, Saúde, Educ, v.7, n.12, p.73-90, 2003.

La práctica de la enfermera en el Servicio de Asistencia Domiciliar (SAD) del Departamento Municipal de Salud de Ribeirão Preto - Brasil es el objeto de esta investigación con el objetivo de presentar cómo están siendo procesadas las tecnologías en la asistencia domiciliar, apuntando a la producción de subjetividades y posibilidades para el trabajo en salud. Fueron utilizados los conceptos relacionados al movimiento institucionalista. Los sujetos fueron enfermeros que trabajan en el SAD y el material empírico fue colectado por la técnica del grupo focal. La ordenación de los datos ocurrió por el método del Discurso del Sujeto Colectivo - DSC. La investigación reveló la potencialidad del SAD para actuar como un agente para la transformación gradual y progresiva de la práctica de salud/enfermería. La vivencia en el SAD ha posibilitado el autocuestionamiento, reflexión y revisión de conductas. Fue destacada la importancia atribuida a las tecnologías leves para el trabajo en salud y principalmente para la asistencia domiciliar, incorporando la dimensión subjetiva inherente a toda producción. Fue posible evidenciar que es un trabajo vivenciado con limitaciones, frustraciones, pero también con comprometimiento, creatividad, responsabilidad y satisfacción, reconociendo el proceso de cambio como gradual, en el cual el trabajador necesita estar dispuesto a aceptar ser revisto y rever el proceso de trabajo.

PALABRAS CLAVE: Cuidados domiciliarios de salud; Enfermería; práctica privada de Enfermería.

Recebido para publicação em: 15/12/01 Aprovado para publicação em: 02/09/02 